\title{
MATRIX-ASSISTED LASER DESORPTION FOURIER TRANSFORM MASS SPECTROMETRY FOR BIOLOGICAL COMPOUNDS*
}

Robert Hettich and Michelle Buchanan

Analytical Chemistry Division

CONF-9006271--2

Oak Ridge National Laboratory

Oak Ridge, TN 37831-6120

submitted for publication in

Proceedings of the NATO Advanced

Workshop on Mass Spectrometry

Minaki, Canada

June 24-28, 1990

* Acknowledgement is given to the Office of Health and Environmental Research, U.S. Department of Energy under contract DE-AC05-84OR21400 with Martin Marietta Energy Systems, Inc. for support of this research.

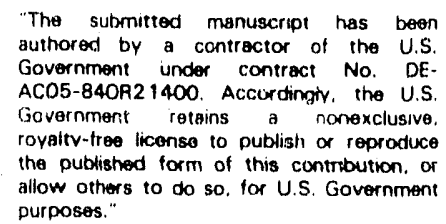

"The submitted manuscript has authored by a contractor of the U.S. Government under contract No. DEACO5-84OR2 1400 . Accurdingtv, the U.S. Government retains a nonexclusive. royaitv-tree license to publish or reproduce the published form of this contribution. or allow others to do so. for U.S. Government
purposes."

\section{DISCLAIMER}

This report was prepared as an account of work sponsored by an agency of the United States Government Neither the United States Government nor any agency thereof, nor any of their employees, makes any warranty, express or implied, or assumes any legal liability or responsibility for the accuracy, completeness, or usefulness of any information, apparatus, product, or process disclosed, or represents that its use would not infringe privately owned rights. Reference herein to any specific commercial product, process, or service by trade name, trademark, manufacturer, or otherwise does not necessarily constitute or imply its endorsernent, recommendation, or favoring by the United States Government or any agency thereof. The views and opinions of authors expressed herein do not necessarily state or reflect those of the United States Government or any agency thereof. 


\title{
Matrix-Assisted Laser Desorption Fourier Transform Mass Spectrometry for Biological Compounds ${ }^{*}$
}

\author{
$\underline{\text { Robert Hettich and Michelle Buchanan }}$
}

Analytical Chemistry Division

Oak Ridge National Laboratory

Oak Ridge, TN 37831-6120

\section{INTRODUCTION}

The recent development of matrix-assisted UV laser desorption (LD) mass spectrometry has made possible the ionization and detection of extrem:sy large molecules (with molecular weights exceeding 100,000 Daltons) [1,2]. This technique has generated enormous interest in the biological community for the direct examination of large peptides and oligonucleotides. Although this matrix-assisted ionization method has been developed and used almost exclusively with time-of-flight (TOF) mass spectrometers, research is currently in progress to demonstrate this technique with trapped ion mass spectrometers, such as Fourier transform ion cyclotron resonance mass spectrometry (FTMS). The potential capabilities of FTMS for wide mass range, high resolution measurements, and ion trapping experiments (for ion-molecule reactions and $\mathrm{MS}^{\mathrm{n}}$ experiments) suggest that this instrumental technique should be useful for the detailed structural characterization of large ions generated by the matrixassisted technique. We have recently demonstrated that matrix-assisted ultraviolet laser desorption, with either 266 or $355 \mathrm{~nm}$ radiation, can be successfully used with FTMS for the ionization of small peptides [3]. The objective of this report is to summarize

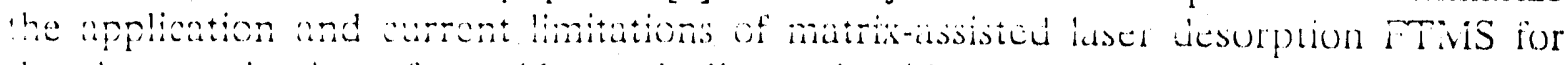
the characterization of peptides and oligonucleotides at the isomeric level.

\section{EXPERIMENTAL}

All experiments were performed with an Extrel FTMS-2000 Fourier transform mass spectrometer ( 3 Tesla magnet) equipped with a Quanta Ray DCR-11 Nd:YAG pulsed laser. The laser was operated in the Q-switched mode (donut-shaped beam, 8 nanosecond pulse width) to generate radiation at 1064, 355, and 266 nanometers. The laser beam was focussed onto the probe tip in an area of approximately $250 \times 250$ microns, giving an estimated power density of low $10^{6} \mathrm{~W} / \mathrm{cm}^{2}$ for $266 \mathrm{~nm}$. Increasing the laser power density above this value resulted in increased fragmentation. in accord with results obtained by other research groups [2]. The experiment was conducted by firing the laser at the beam event to ionize the sample. Immediately following the laser pulse, an ejection pulse (150 millisecond duration) was used to eliminate either the $(\mathrm{M}+\mathrm{H})^{+}$or $(\mathrm{M}-\mathrm{H})^{-}$ions of the matrix compound, depending on whether negative or positive ions were examined. This event was followed by broad band excitation and detection of the ion cyclotron signal. A complete mass spectrum could be obtained from a single läser shot, alihough signal averaging was used tó vitain betier specira. 
The samples were prepared by mixing one microliter of an aqueous analyte solution (approximately $10^{-4} \mathrm{M}$ ) with a few microliters of an aqueous matrix solution (approximately $10^{-2} \mathrm{M}$ ), based on experimental conditions outlined for the TOF experiments [1,2]. A few microliters of this resulting solution was then dried onto the tip of a stainless steel solids probe tip used for the laser desorption experiments. Although the detection limit of the technique was not examined in detail. generally 10 100 picomoles of analyte was placed on the probe tip, although this amount certainly exceeds that required for the laser desorption process.

Even though both TOF and FTMS are pulsed techniques and can be interfaced with pulsed laser desorption/ionization, there are several important differences between these two mass spectral techniques. First, the time scales of the two techniques are dramatically different. Ion detection in FTMS occurs tens to hundreds of milliseconds after ion formation, whereas the TOF instruments utilize much shorter time scales (typically microseconds). More important is the fact that fragmentation of a large ion in the flight tube of a TOF does not affect its detection, because the fragment ions arrive at the detector at the same time that the undissociated parent would have arrived. Thus ion fragmentation is more readily observed in the FTMS experiments as compared to TOF measurements. Second, because the FTMS is an ion trap technique, it has a limited dynamic range (approximately $10^{\circ}$ ). This implies that the analyte cannot be too dilute in the presence of the excess matrix, or the analyte ions will nut be observed. Third, ion detection by FTMS is accomplished by monitoring ion image current on the receiver plates, as opposed to ion detection by an electron multiplier in TOF. This difference implies that while FTMS cannot count single ions, it does not suffer from multiplier insensitivity to large ions. However, the successful detection of large ions $(\mathrm{m} / \mathrm{z}>50,000)$ by FTMS has not yet been realized, and may be currently limited by instrumental factors of the FTMS [4].

\section{RESULTS AND DISCUSSION}

\section{Peptides}

Following protocols outlined by Karas and Hillenkamp [1], $266 \mathrm{~nm}$ laser desorption FTMS using nicotinic acid (3-pyridine carboxylic acid) as the matrix was examined for peptides. This matrix-assisted ionization technique dramatically improved the abundance of the intact molecular $(\mathrm{M}+\mathrm{H})^{+}$or adduct $(\mathrm{M}+\mathrm{Na})^{+},(\mathrm{M}+\mathrm{K})^{+}$ions. Even for compounds like leucine enkephalin and methionine enkephalin which yield $(\mathrm{M}+\mathrm{H})^{+}$ions under laser desorption conditions without using a matrix, the addition of a nicotinic acid matrix significantly enhanced the abundance of molecular ions while reducing the amount of fragmentation observed. Winile laser desorption of larger peptides like Substance $P$ without a matrix present yields virtually no $(\mathrm{M}+\mathrm{H})^{+}$ions, the use of a nicotinic acid matrix provides remarkable signal enhancement for $(\mathrm{M}+\mathrm{H})^{+}$ and $(\mathrm{M}+\mathrm{Na})^{+}$ions. Laser desorption using $266 \mathrm{~nm}$ and a nicotinic acid matrix was useful for generating molecular jons for peptides with molecular weights up to at least 2000 Daltons, as shown in Table 1. This table lists the UV laser desorption of peptides using a variety of matrices $\left(+\right.$ indicates that $(\mathrm{M}+\mathrm{H})^{+}$or $(\mathrm{M}+\mathrm{Na})^{+}$ions werc observed, - indicates that no molecular ions were observed). Initial investigations of large peptides, such as bovine insulin A-chain ( $\mathrm{MW}=2535$ ) and bovine insulin ( $\mathrm{MW}$ $=5733.5$ ), failed to reveal molecular or tragment ions using the experimental conditions outlined above. 
Table 1. Effect of laser wavelength and matrix composition on laser desorption a

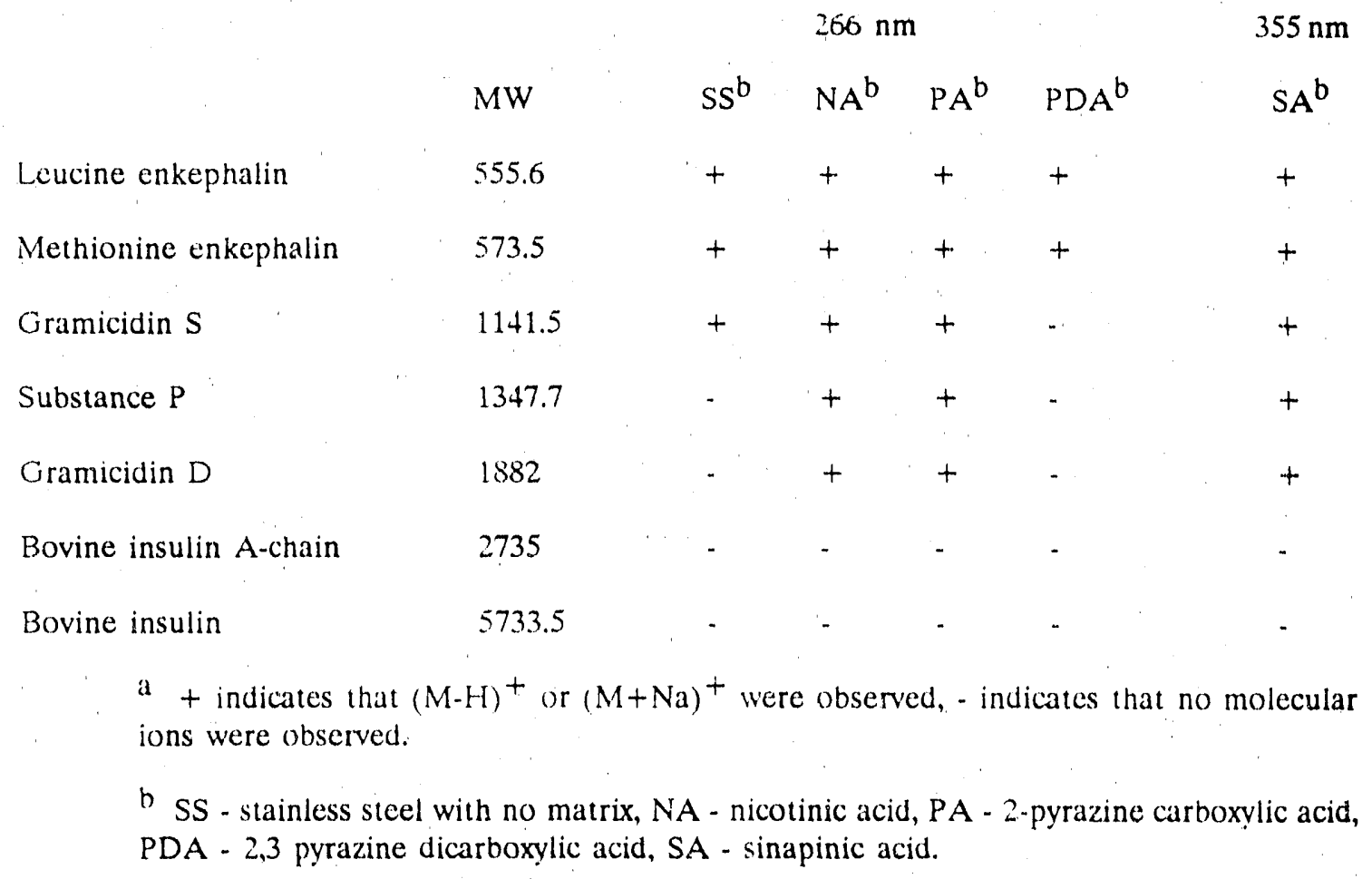

These results may imply that ion detection with conventional FTMS hardware under these experimental conditions may be the limiting factor rather than ion formation. Extensive research is underway in our laboratory as well as many other FTMS labs to address FTMS ion detection limitations for biological compounds [4].

Chait and coworkers have examined a variety of matrices and have determined that 2-pyrazine carboxylic acid can also be used for $266 \mathrm{~nm}$ laser desorption experiments [2]. As shown in Table 1, this matrix works as well as nicotinic acid for the FTMS experiments, and reveals the same mass limitation. The ionization - nhancement is strongly denerdent on the chemical structure of the matrix compound. For example, 2,3-pyrazine dicarboxylic acid was found not to provide matrix enhancement for the $266 \mathrm{~nm}$ laser desorption FTMS experiments, even though this compound is structurally quite similar to pyrazine carboxylic acid. This experiment supports results obtained by TOF experiments [2] and verifies matrix-assisted enhancement of the FTMS experiments as opposed to differences in sample preparation.

Because many compounds absorb radiation at $266 \mathrm{~nm}$, laser desorption at this wavelength usually excites both the matrix and the analyte, often resulting in fragmentation of the analyte. To avoid this problem, alternate wavelengths and appropriate matrices can be chosen to minimize spectra absorption by the analyte. Chait and coworkers have reported that sinapinic acir (3,5-dimethoxy-4hydroxycinnamic acid) provides an excellent matrix for the $355 \mathrm{~nm}$ laser desorption of peptides [2]. Results obtained with FTMS confirm the success of this method, shown in Table 1. No significant differences in fragmentation were observed for the peptides examined here at the two different wavelengths. This wavelength dependence should be more pronounced for compounds which absorb strongly at $266 \mathrm{~nm}$, such as (iligonucleotides. The absence of $(\mathrm{M}+\mathrm{H})^{+}$ions for $355 \mathrm{~nm}$ laser desorption FTMS of peptides with $\mathrm{MW}>2500$ supports the $266 \mathrm{~nm}$ results and once again alludes to ine current instrumental limitations of FTMS. 
Based on the success of matrix-assisted laser desorption FTMS for peptides, we decided to examine normal and modified oligonucleotides. Molecular ions from these compounds are quite difficult to obtain by laser desorption due to the ease of breaking the weak glycosidic bonds of the oligonucleotide. Examination of these oligomers without using the matrices indicated extensive fragmentation $t$ () produce the nucleic base ions, with virtually no fragment ions indicative of the sequence of the oligomer. However, matrix-assisted laser desorption using $266 \mathrm{~nm}$ and nicotinic acid was useful for generating (M-H) ions for small oligonucleotides. Even though the oligomers absorb at this wavelength, characteristic negative ions such as (M-H) and fragment ions were observed which provided detailed sequence information. The negative ion spectra were the most informative for these compounds. Matrix-assisted $355 \mathrm{~nm}$ laser desorption FTMS has not been investigated for oligonucleotides at the present time.

Oligonucleotide dimers can be asily characterized with this technique. Figures 1 and 2 illustrate the negative ion spectra obtained for two isomeric dimers, $d(G A)$ and $\mathrm{d}(\mathrm{AG})$. Although $(\mathrm{M}-\mathrm{H})^{-}$ions at $\mathrm{m} / \mathrm{z} 579$ are observed for each isomer, fragment ions are observed which result from loss of the nucleic bases as well as preferential cleavage of the phosphate ester linkage from the 3 ' end of the oligomer. This latter fragmentation pathway generates $\mathrm{m} / \mathrm{z} 346$ as the most abundant sequence ion from $\mathrm{d}(\mathrm{AG})$, while $\mathrm{m} / \mathrm{z} 330$ is the most abundant sequence ion from $\mathrm{d}(\mathrm{GA})$. These ions provide the infurmation nocessary to identify the 3 ' end of the oligomers and differentiate the isomers. A modified oligonucleotide dimer $\mathrm{d}(\mathrm{Tp} T)$ containing ethylation of the phosphate linkage was also examined with this method. An (M-H) ion was observed at $\mathrm{m} / \mathrm{z} 574$ as well as fragment ions at $\mathrm{m} / \mathrm{z} 546\left(\mathrm{M}_{-} \mathrm{C}_{2} \mathrm{H}_{4}\right)^{-}$and $\mathrm{m} / \mathrm{z}$ 349 (cleavage of the phosphate linkage). Isolation and collision-induced dissociation of the $\mathrm{m} / \mathrm{z} 349$ ion generated several fragment ions, including $\mathrm{m} / \mathrm{z} 125$ which was presumed to be the thymine nucleic base. However, close examination of the ion at nominal $\mathrm{m} / \mathrm{z} 125$ revealed two ions, $\mathrm{m} / \mathrm{z} 125.03565\left(\mathrm{C}_{5} \mathrm{H}_{5} \mathrm{~N}_{2} \mathrm{O}_{2}{ }^{\circ}\right.$ of thymine) and $125.00092\left(\mathrm{PO}_{4} \mathrm{C}_{2} \mathrm{H}_{6}{ }^{-}\right)$. In this case, a resolution of greater than 3500 (FWHM) was needed to resolve these two isobaric ions and verify the position of ethyl substitution an the nhosnhate linkare for this rimer

Examination of oligonucleotide trimers also provided molecular weight and sequence information. Two trimers, $\mathrm{d}(\mathrm{GGT})$ and $\mathrm{d}(\mathrm{TGT})$, were examined with this matrix-assisted technique. For d(GGT), a molecular ion (M-H) at $\mathrm{m} / \mathrm{z} 899$ was observed along with abundant fragment ions at $\mathrm{m} / \mathrm{z} 650$ and 321 , which provided the sequence information for the cligomer. Note that these ions result from fragmentation from the $3^{\prime}$ end and would provide differentiation of $\mathrm{d}\left(5^{\prime}-\mathrm{GGT}-3^{\prime}\right)$ from $\mathrm{d}\left(5^{\prime}-\mathrm{TGG}\right.$ 3'). Examination of $\mathrm{d}(\mathrm{GGT})$ under the same experimental conditions (i.e. laser wavelength, energy, sample concentration) without nicotinic acid as the matrix indicated almost complete loss of sequence information. The only ion observed in this case was the $\mathrm{m} / \mathrm{z} 321$ ion, corresponding to the terminal thymidine phosphate residue of the oligomer. Isolation and collisional dissociation of the (M-H) at $\mathrm{m} / 899$ for $\mathrm{d}(\mathrm{GGT})$ gave the same fragment ions as observed in the laser desorption experiment. Laser desorption of the trimer d(TGT) yielded characteristic negative ions corresponding to (M-H) at $\mathrm{m} / \mathrm{z} 874$ and the $3^{\prime}$ cleavage ions at $\mathrm{m} / \mathrm{z} 650$ and 321 , which provided the sequence information for this trimer.

A series of oligonucleotide tetramers, including four d(CGCG) isomers, were examined to ascertain the level of sequence information available from the fragment ions. The isomeric d(CGCG) set included not only positional isomers such as ¿ $(\mathrm{CGC})$ and $4(C \mathrm{CGG})$ but also compounds ditfering only in the location of the 3' 


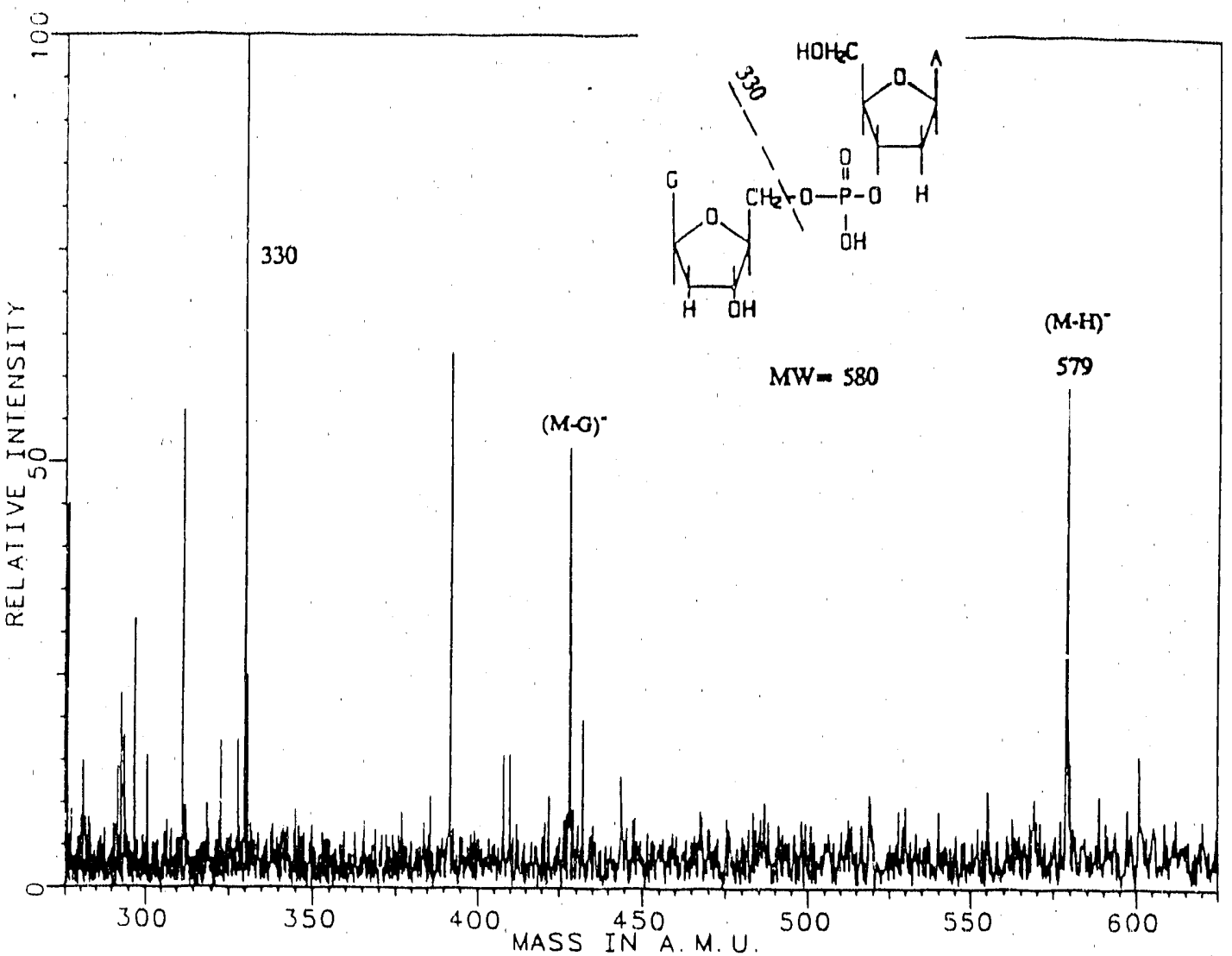

Figure 1 Negative ion FTMS spectrum of $d(G A)$ using $266 \mathrm{~nm}$ laser desorption with a nicotinic acid matrix.

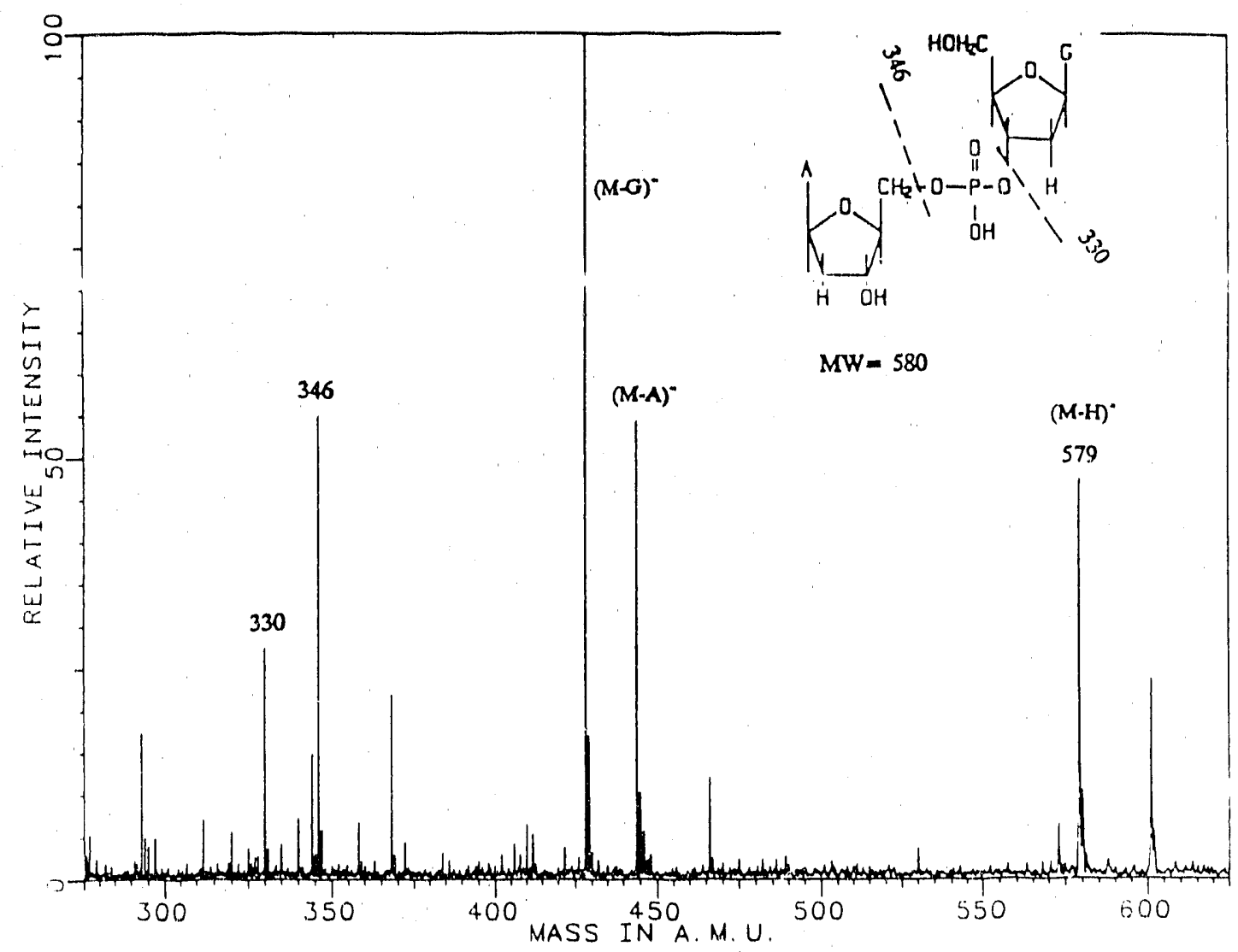

Figure 2 Negative ion FTMS spectrum of $d(A G)$ using $266 \mathrm{~nm}$ laser desorption with a nicotinic acid matrix. 
end such as d(5'-CGCG-3') and d(5'-GCGC-3'). Characteristic (M-H)' ions as well as ions corresponding to tragmentation predominantly from the $3^{\prime}$ end of the tetramer were observed, as shown in Figure 3 for d(CGCG). Substantial fragmentation of the tetramer is observed under these experimental conditions, as might be expected since these oligonucleotides absorb readily at the $266 \mathrm{~nm}$ laser desorption irradiation. Even though many different fragment ions are observed, examination of the four spectral regions outlined in Figure 3 were sufficient to determine the sequence of this tetramer. Note that $(\mathrm{M}-\mathrm{G})^{-}$at $\mathrm{m} / \mathrm{z} 1022$ is observed while $(\mathrm{M}-\mathrm{C})^{-}$is completely absent. This nucleic base elimination is assumed to originate from the $3^{\prime}$ end of the tetramer, as evident in Table 2. This fragment ion, along with the sequence ions, enables isomeric differentiation of oligomers which are identical in sequence and differ only in the assignment of the 3' end. Sequence ions resulting from fragmentation of the 5' end of the tetramers were observed in minor abundance, especially when a cytosine residue was at the 3' end of the oligomer, and provided additional sequence information. The negative ions obtained for a oligonucleotide containing all four DNA bases, d(TGCA), are listed in Table 2. An $(\mathrm{M}-\mathrm{H})^{-}$ion at $\mathrm{m} / \mathrm{z} 1172$ was observed as well as sequence ions at $\mathrm{m} / \mathrm{z} 948,618$, and 330 (from 3' end). For this tetramer, no characteristic (Mbase) ion was observed. Examination of a modified version of this tetramer, $1\left(\mathrm{TG}^{*} \mathrm{CA}\right)$ where $\mathrm{G}^{*}$ is $\mathrm{O}^{\circ}$-methyl guanine, indicated an $(\mathrm{M}-\mathrm{H})^{-}$ion at $\mathrm{m} / \mathrm{z} 1186$ and characteristic fragment ions as shown in Table 2. The first two sequence ions $(\mathrm{m} / \mathrm{z} 330$ and 618) are identical to those observed for the tetramer d(TGCA); however, the 3rd sequence ion at $\mathrm{m} / \mathrm{z} 962$ is 14 amu higher than the analogous ion for d(TGCA), verifying that methyl adduction occurs at this position.

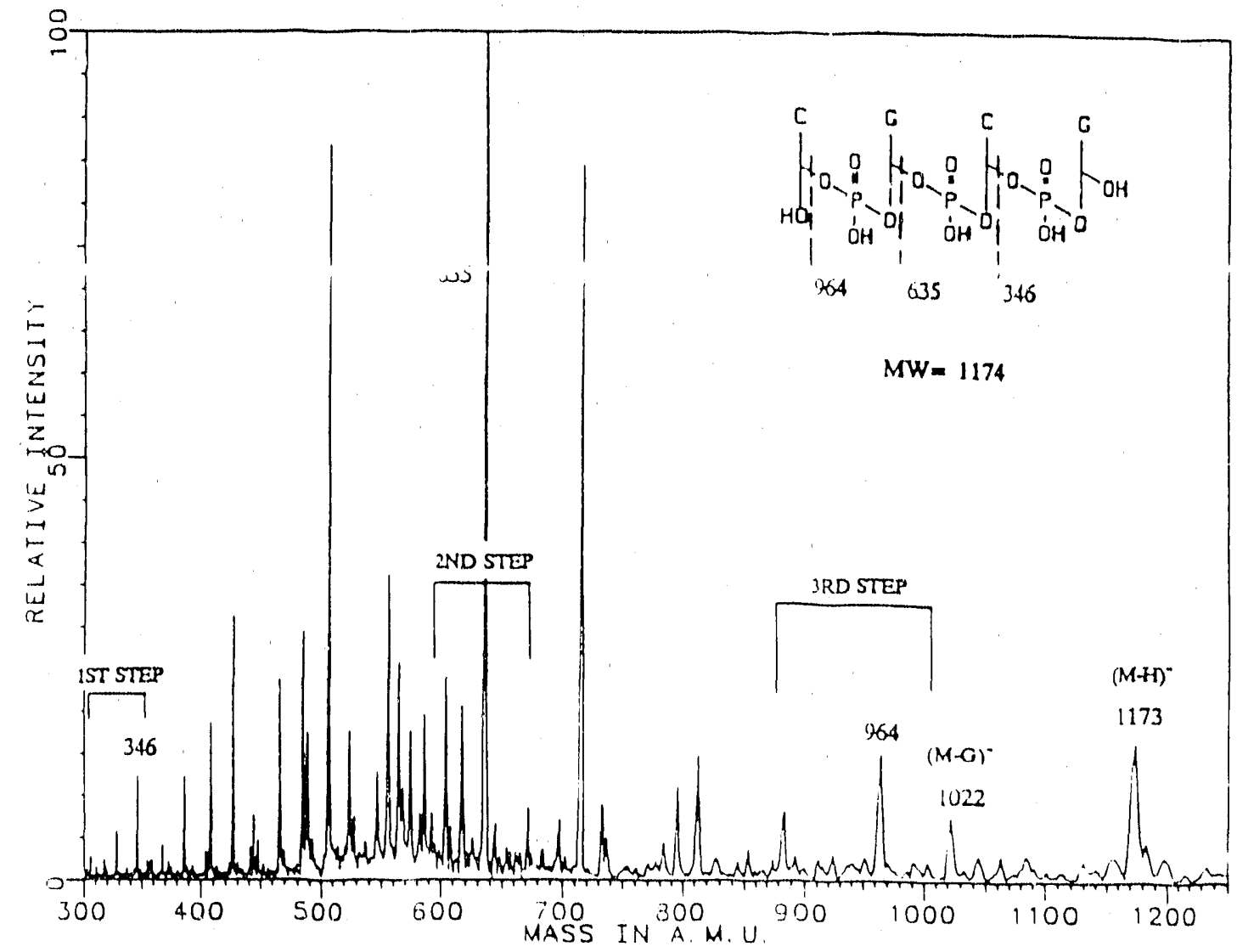

Figure 3 Negative ion FTMS spectrum of d(CGCG) using $266 \mathrm{~nm}$ laser desorntion with a acounic acia matrax. 
Table 2 Oligonuclcotide tetramer sequence ions obtained by $266 \mathrm{~nm}$ laser desorption.

\begin{tabular}{|c|c|c|c|c|}
\hline Tetramer & $(\mathrm{M}-\mathrm{H})^{-}$ & (M-base) $)^{-}$ & Scquisnce ions & \\
\hline$d(C G C G)$ & 1173 & $(\mathrm{M}-\mathrm{G})^{-}$ & $964,635,246$ & $\left(3^{\prime}\right.$ end $)$ \\
\hline $\mathrm{d}(\mathrm{GCGC})$ & 1173 & $(\mathrm{M}-\mathrm{C})^{-}$ & $\begin{array}{l}924,635,3166 \\
964,635,346\end{array}$ & $\begin{array}{l}\text { (3' end) } \\
\text { (5' end) }\end{array}$ \\
\hline $\mathrm{d}(\mathrm{CCGG})$ & 1173 & $(\mathrm{M}-\mathrm{G})^{-}$ & $964,675,346$ & ( $3^{\prime}$ end) \\
\hline $\mathrm{d}(\mathrm{GGCC})$ & 1173 & $(\mathrm{M}-\mathrm{C})^{-}$ & $\begin{array}{l}924,595,306 \\
964,675,346\end{array}$ & $\begin{array}{l}\left(3^{\prime} \text { end }\right) \\
\left(5^{\prime} \text { end }\right)\end{array}$ \\
\hline $\mathrm{d}(\mathrm{TGCA})$ & 1172 & - & $948,618,330$ & ( 3 ' end $)$ \\
\hline $\mathrm{d}\left(\mathrm{TG}^{*} \mathrm{CA}\right)$ & 1186 & - & $962,618,330$ & $\left(3^{\prime}\right.$ end $)$ \\
\hline
\end{tabular}

The largest oligonucleotide observed to date by matrix-assisted laser desorption FTMS is the hexamer d(GCTAGC) with a molecular weight MW $=1791$. The negative ion spectrum revealed an $(\mathrm{M}-\mathrm{H})^{-}$ion at $\mathrm{m} / \mathrm{z} 1790$ as well as several sequence ions. The most abundant fragment ions observed for this oligomer were due to cleavage of every second phosphate linkage from the $\mathrm{m} / \mathrm{z} 1790 \mathrm{ion}$, forming $\mathrm{m} / \mathrm{z} 1252$ and 635. Examination of larger oligonucleotides failed to reveal molecular ions, implying that ion detection factors may currently limit the useable mass range. Further research is in progress to investigate these limitations for large oligonucleotides.

\section{CONCLUSIONS}

Matrix-assisted UV laser desorption FTMS has heen demonstrated for hoth peptides and uligonucleotides with molecular weights up to 2000 Daltons. The choice of matrices and laser wavelengths for the FTMS experiments agree very well with results obtained by TOF experiments and verify the matrix enhancement effects for FTMS. Either 266 or $355 \mathrm{~nm}$ can be used with the appropriate matrices to generate $(\mathrm{M}+\mathrm{H})^{+}$ions for small peptides. Examination of oligonucleotides using $266 \mathrm{~nm}$ and it nicotinic acid matrix revealed $(\mathrm{M}-\mathrm{H})^{-}$ions as well as many fragment ions, which provided the information necessary to determine the oligomer sequence at the isomeric level for oligonucleotide dimers up to hexamers. The lack of observation for peptide and oligonucleotide ions at $\mathrm{m} / \mathrm{z}>2500$ may imply that current FTMS ion detection factors under these experimental conditions limit the detection of large ions. Further work is in progress to investigate and reduce these limitations using larger magnets, alternate cell designs, and ion manipulation techniques. 
1. M. Karas and F. Hillerıkamp, Analytical Chemistry 60, (1988) 2299.

2. R. C. Beavis and B. T. Chait, Rapid Comm. Mass Spec. 3, (1989) 233.

3. R. L. Ilettich and M. V. Buchanan, J. Amer. Soc. Mass Spec., submitted June 1990.

4. For a review of the current status of FTMS, see: C. L. Wilkins, A. K. Chowdhury, L. M. Nuwaysir and M. L. Coates, Mass Spec. Rev. 8, (1989) 67.

Acknowledgement is given to the Office of Health and Environmental Research, U.S. Department of Energy under contract DE-AC05-84OR21400 with Martin Marietta Energy Systems, Inc. for support of this research.

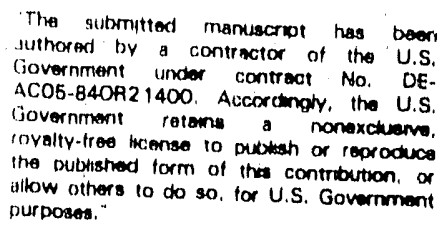


